\title{
Is snacking the new smoking?
}

\section{EDITORIAL}

Melbourne Clinical School, University of Notre Dame Australia, Melbourne, VIC, Australia

To Cite: Jiwa M, Krejany, C, Kanjo E. Is snacking the new smoking? JHD. 2021;6(1):346-350. https://doi.org/10.21853/JHD.2021.124

\section{Corresponding Author:}

Moyez Jiwa

Melbourne Clinical School, School of Medicine, Sydney University of Notre Dame Australia Moyez.jiwa@nd.edu.au

\section{Copyright:}

(C2021 The Authors. Published by Archetype Health Pty Ltd. This is an open access article under the CC BY-NC-ND 4.0 license.

\section{SUMMARY}

The way we eat is changing. Incrementally, between-meal snacking has increased over time, and our busy, on-the-run lifestyles and changing social norms fuel the consumption of convenience foods and calorie-dense snacks. The societal normalising of snacking behaviour has myriad influences, but the marketing narrative that snacking is "good for you" needs to be challenged. Cigarette promotion of yesteryear seems unconscionable today, but the way snack foods are now pitched to the public has some eerie parallels. The pervasiveness of aggressive targeted marketing, celebrity endorsement, social normalisation narrative, and dismissal of health consequences should give us pause for thought.

\section{Key Words}

Snacking; obesity; eating frequency; eating behavior; smoking cessation

\section{INTRODUCTION}

Obesity is our greatest global public health challenge. Obesity greatly increases the risk of diabetes, heart disease, cancer, and a host of other chronic and life-limiting illnesses. The World Health Organization has coined the term "globesity" with respect to the global nature of this challenge to world health. ${ }^{1}$ The need to do something to reverse the trend of expanding waistlines has become a priority. Authors of a British Medical Journal review commenting on one significant root of the problem stated:

The obesity pandemic is the result of living in food environments where it is difficult not to overconsume calories. The global food industry produces and extensively promotes cheap, sugar sweetened beverages, and ultraprocessed foods high in salt, sugar, and saturated fat that provide only a transient sensation of fullness. Governments have done too little, with one of the few successes being taxes on sugar sweetened beverages-in particular, the industry levy in the UK that has resulted in reformulation to reduce the sugar content. ${ }^{2}$

The COVID-19 pandemic has made matters worse by accelerating the rate of increase for the prevalence of being overweight or obese. ${ }^{2}$ Isolation, economic burden, and personal loss combined with sustained periods of lockdown have seen increases in both food and beverage consumption-in particular, alcohol-as people attempt to cope with a removal of familiarity and social norms. The pandemic represents a sudden disruption to patterns and practices of eating in response to extreme stress. However, many scholars contend our eating practices have been evolving for some time. In particular, we have moved away from structured eating: three meals a day consisting of breakfast, lunch and dinner, to more irregular and informal eating behaviour where there is now a fine line between snacking and mealtimes. ${ }^{3}$ Motivations for snacking have been well studied and marketers who wish to promote the behaviour and sell more product are 
well aware of these triggers and actively seek to exploit them. Consequently, the changing culture of eating and the availability of snacks is contributing to increased eating frequency patterns and excess weight gain. ${ }^{4}$

There are strong parallels with how cigarettes were promoted before the universal acceptance of the evidence that tobacco smoke is a risk factor for myriad human diseases. Recent literature has also suggested that cigarette manufacturers deploy tactics that promote the idea that smoking may enhance the experience of life events for those who might be future customers, such as leaving home, going to college, or starting work. ${ }^{5}$ Similarly, the food industry promotes the consumption of sugary, calorie dense snacks on a narrative that encourages consumers to equate these products with pleasure, relaxation, and reward:

Sweet snacks are more likely to be seen as a 'treat', a special kind of snack often couched in terms of self-reward. Here the role of manufacturers in the construction of taste and its cultural circulation and stratification in interplay with human corporeality should not be discounted from thinking about the sensual enrolment of new practitioners in a wider range of snacking practices. ${ }^{3}$

In recent times we have also seen the advent of "healthy snacks" and the use of health claims to sell these convenience products. Labels such as "higher in protein", "low fat", or "added antioxidants" suggest consumers can choose a healthier option compared to a competing product. Social marketers aim to sell behaviours, not just products, and while this approach has the potential to make positive behavior change and health promotion at a population level ${ }^{6}$, there is competition with industries that seek to promote behaviours that lead to increased market productivity. For example, the makers of cookies, crackers, and chocolate, are quoted as saying:

Wellbeing is evolving to be more holistic and in line with people's lifestyle and values. Consumers are increasingly aware of the connection between what they eat and how they feel-physically and emotionally. We know people want convenient and delicious snacks they feel good about eating... We're focused on redesigning the experience of snacking, to help our consumers get what they need from the snacks and brands they love. We are cultivating healthier eating habits by promoting a mindful approach to snacking, and inspiring more enjoyable snacking experiences. ${ }^{?}$

As snacking becomes a more accepted and normalised behaviour, we need to be mindful of who is controlling this narrative and reflect on the consequences of such behaviour. How then will the habit of snacking be regarded in years to come? Currently, snacking is engrained in the cultural, work, and family life of the community. Much can be learned from how cigarette smoking came to have a role in the emotional life of individuals who smoked. For example, in one study it was demonstrated that those with stressful or unrewarding jobs were more likely to be smokers. ${ }^{8}$ In another study, psychosocial stress was shown to increase smoking desire. ${ }^{9}$ Research suggests stress reduction and relaxation were the most frequently cited reasons why young women smoked. Stress-inducing situations included family environment, social relations with classmates, and schoolwork. ${ }^{10}$ Similarly, the reasons for consuming sweet and high-density snacks have been couched in analogous terms. In one experiment when subjects were stressed, they were more likely to choose to eat sugary "unhealthy" snacks. ${ }^{11}$ Similarly, higher frequency of so-called "emotional eating" has been shown to be associated with the consumption of sweet and fatty foods. ${ }^{12}$ 
Parallels exist between how tobacco smoking and the consumption of sugary snacks are associated with the notion of reward and pleasure. This association is reinforced on a physiological scale. While smoking activates dopamine-based reward systems in the brain via nicotine in cigarettes, eating drives are more complex and involve both homeostatic and hedonic mechanisms of control. Homeostatic pathways operate to regulate appetite based on whether the energy requirements of the body are in depletion or excess. Hedonic eating can be a part of homeostatic processes but also operates independently in response to palatable foods high in sugar, fat, and salt. ${ }^{13}$ These reward-based hedonic mechanisms can override normal homeostatic processes that control weight gain. Individuals with obesity have been shown to have both an increased food attention to high-energy dense foods and also have an increased activation of the hedonic pathways that drive appetite when palatable food is ingested. For obese individuals attempting to control their weight the challenge is intensified when snack foods are so readily available, societally normalised, and act as rewards on both an emotional and physiological level.

With the benefit of hindsight, it is possible to see how smoking was finally recognised as harmful and how the narrative around smoking was reworked. Many of the conduits that promoted tobacco smoking are now recognised and, where possible, erased. For example, smoking is restricted in the images displayed to adolescents at the cinema,${ }^{14}$ and the idea that smoking is a suitable option to help relieve stress is no longer tolerated. ${ }^{15}$ Similarly, we can already demonstrate that eating sugary snacks does not reduce hunger and is more likely to increase food intake in the absence of hunger. ${ }^{16}$ As was the case for smoking, the cumulative exposure to television food advertising and other food marketing sources are positively linked to adolescents' food choices and eating behaviours. Policy changes to restrict food marketing to young people should include both television and non-broadcast media. ${ }^{17}$

Looking at the promotion of smoking in the media now seems ludicrous. ${ }^{18}$ Perhaps in the future we will also find ourselves reflecting on how we came to "normalise" snacking behaviour, and it will be seen in the same harmful light. If snacking follows the same trajectory as smoking in terms of recasting it as "harmful", the way forward has been identified by the tobacco cessation movement. They include the following elements:

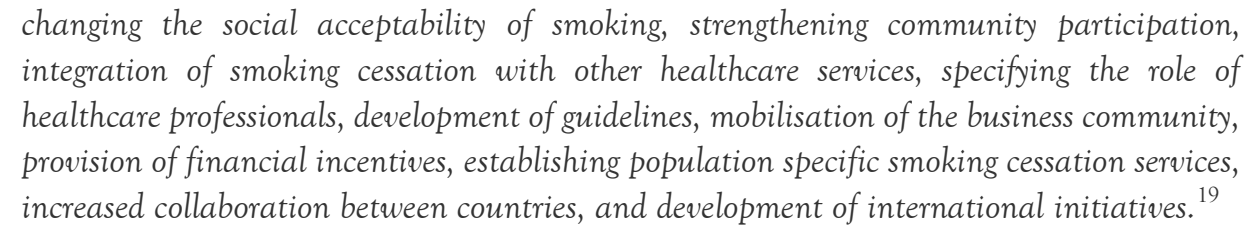

There is a lot of work to be done, but the cost of inaction was clear from the tobacco smoking corollary where some elements were only actioned late-for example, the ban on tobacco advertising-but the results when that action was taken were remarkable. ${ }^{20}$ It may be time to consider how we are triggered to consume to excess and do something about it. The precise role of an already overstretched healthcare system needs further work. It could be argued that whatever the role of health care, it will only be a very small part of the jigsaw puzzle.

\section{REFERENCES}

1. World Health Organisation. Controlling the global obesity epidemic. [cited 2020 Sept 7]. Available from: https://www.who.int/nutrition/topics/obesity/en/

2. Tan M, He FJ, MacGregor GA. Obesity and covid-19: the role of the food industry. BMJ. 2020;369:m2237 doi: 10.1136/bmj.m2237

3. Twine R. Understanding snacking through a practice theory lens. Sociol Health Illn. 2015;37: 1270-84. doi: $10.1111 / 1467-9566.12310$ 
4. Hunter S.R., Mattes R.D. The role of eating frequency and snacking on energy entake and BMI. In: Meiselman H. (ed). Handbook of Eating and Drinking. Springer, Cham. 2020. Doi: 10.1007/978-3-030-14504-0_115

5. Ling PM, and Glantz SA. Why and how the tobacco industry sells cigarettes to young adults: evidence from industry documents. Am J Public Health. 2002;92:908-16. doi: 10.2105/AJPH.92.6.908

6. Douglas EW. How social marketing works in health care. BMJ. 2006;332:1207. doi: 10.1136/bmj.332.7551.1207-a

7. Mondeléz International. State of snacking. 2019 Global consumer snacking trends study. [cited 2020 Sept 10]. Available from: https://www.stateofsnacking.com/wpcontent/uploads/2019/11/2019_MDLZ_stateofsnacking_report_GLOBAL_EN.pdf

8. Kouvonen A, Kivimäki M, Virtanen M, et al. Work stress, smoking status, and smoking intensity: an observational study of 46190 employees. Journal of Epidemiology $\mathcal{E}$ Community Health. 2005;59:63-9. doi: 10.1136/jech.2004.019752

9. Childs E, and de Wit H. Effects of acute psychosocial stress on cigarette craving and smoking. Nicotine Tob Res. 2010;12(4):449-453. doi: https://doi.org/10.1093/ntr/ntp214

10. Nichter M, Nichter M, Vuckovic N, et al. Smoking experimentation and initiation among adolescent girls: qualitative and quantitative findings. Tob Control. 1997;6(4):285-95. doi: 10.1136/tc.6.4.285

11. Zellner DA, Saito S, and Gonzalez J. The effect of stress on men's food selection. Appetite. 2007;49(3):696-9. doi: https://doi.org/10.1016/j.appet.2007.06.013

12. Camilleri GM, Méjean C, Kesse-Guyot E, et al. The associations between emotional eating and consumption of energy-dense snack foods are modified by sex and depressive symptomatology. J Nutr. 2014;144(8):1264-73. doi: 10.3945/jn.114.193177

13. Monteleone AM, Di Marzo V, Monteleone P, et al. Responses of peripheral endocannabinoids and endocannabinoid-related compounds to hedonic eating in obesity. Eur J Nutr. 2016;55: 1799-1805. Doi: 10.1007/s00394-016-1153-9

14. Charlesworth A, and Glantz SA. Smoking in the movies increases adolescent smoking: A review. Pediatrics. 2005;116(6):1516-52. doi:10.1542/peds.2005-0141

15. Smith EA, Malone RE. Mediatory myths in the U.S. military: tobacco use as 'stress relief]. Am J Health Promot. 2014;29(2):115-22. doi: 10.4278/ajhp.121009-QUAL-491

16. Lemmens SG, Rutters F, Born JM, et al. Stress augments food 'wanting' and energy intake in visceral overweight subjects in the absence of hunger. Physiol Behav. 2011;103(2):157-63. doi: 10.1016/j.physbeh.2011.01.009

17. Scully M, Wakefield M, Niven P, et al. Association between food marketing exposure and adolescents' food choices and eating behaviors. Appetite. 2012;58(1):1-5. Doi: 10.1016/j.appet.2011.09.020

18. Romano T. Early 1960s cigarette ads [video file]. 2009 Jul 5 [cited 2020 Sept 10]. Available from: https://www.youtube.com/watch? $=$ =uyCl3BdlICY

19. Abdullah ASM, Husten CG. Promotion of smoking cessation in developing countries: a framework for urgent public health interventions. Thorax. 2004;59:623-30. doi: thx.2003.018820

20. Harris F, MacKintosh AM, Anderson S, et al. Effects of the 2003 advertising/promotion ban in the United Kingdom on awareness of tobacco marketing: findings from the International Tobacco Control (ITC) Four Country Survey. Tob Control. 2006;15:iii26-33. Doi: $10.1136 /$ tc. 2005.013110

\section{ACKNOWLEDGEMENTS}

None 
The
Journal of JHD 2021:6(1):346-350
Health Design

EDITORIAL

\section{PEER REVIEW}

Not commissioned. Externally peer reviewed.

\section{CONFLICTS OF INTEREST}

The authors declare that they have no competing interests.

\section{FUNDING}

None

ETHICS COMMITTEE APPROVAL

None 